\title{
Sustainable affordability of Otago exercise in the US healthcare system: response to Liu et al.
}

\author{
T. Mori ${ }^{1,2,3}$ - C. J. Crandall ${ }^{4}$ - D. A. Ganz $\mathbf{G}^{5,6,7}$
}

Received: 24 March 2017 / Accepted: 12 April 2017 /Published online: 18 May 2017

(C) International Osteoporosis Foundation and National Osteoporosis Foundation 2017

\section{Dear Editor,}

We thank Liu and colleagues [1] for their valuable comments on our article [2]. We agree that performing a costeffectiveness analysis of the combined strategy of oral bisphosphonate therapy and falls prevention exercise from a healthcare perspective is an important area for future work, as recommended by the Second Panel on Cost-Effectiveness in Health and Medicine [3].

\section{References}

1. Liu X, Villamagna AH, Yu JW (2017) Sustainable affordability of Otago exercise in the U.S. healthcare system. Osteoporos Int. doi:10. 1007/s00198-017-4055-7

2. Mori T, Crandall CJ, Ganz DA (2017) Cost-effectiveness of combined oral bisphosphonate therapy and falls prevention exercise for fracture prevention in the USA. Osteoporos Int 28:585-595. doi:10. 1007/s00198-016-3772-7

3. Sanders GD, Neumann PJ, Basu A, Brock DW, Feeny D, Krahn M, Kuntz KM, Meltzer DO, Owens DK, Prosser LA (2016) Recommendations for conduct, methodological practices, and reporting of cost-effectiveness analyses: second panel on costeffectiveness in health and medicine. JAMA : the journal of the American Medical Association 316:1093-1103

\section{T. Mori}

takahiromori@outlook.com

1 Department of General Internal Medicine, Eastern Chiba Medical Center, Tougane City, Chiba, Japan

2 Department of General Medical Science, Graduate School of Medicine, Chiba University, Chiba City, Chiba, Japan

3 Department of Health Services Research, Faculty of Medicine, University of Tsukuba, Tsukuba City, Ibaraki, Japan

4 Division of General Internal Medicine and Health Services Research, Department of Medicine, David Geffen School of Medicine at University of California, Los Angeles, Los Angeles, CA, USA

5 Geriatric Research, Education and Clinical Center and HSR\&D Center for Healthcare Innovation, Implementation and Policy, Veterans Affairs Greater Los Angeles Healthcare System, Los Angeles, CA, USA

6 Division of Geriatrics, Department of Medicine, David Geffen School of Medicine at University of California, Los Angeles, Los Angeles, CA, USA

7 Health Unit, RAND Corporation, Santa Monica, CA, USA 